\title{
Diabetes-Related Distress and Its Associated Factors Among Patients with Diabetes in Vietnam
}

This article was published in the following Dove Press journal:

Psychology Research and Behavior Management

\author{
Van Bang Nguyen (ID) \\ Tam Thi Tran' \\ Thi Ly Dang' \\ Van Vy Hau Nguyen' \\ Binh Thang Tran $\mathbb{D I}^{2}$ \\ Chi Van Le $\mathbb{1}^{3}$ \\ Nguyen Dinh Toan (D) $^{3}$ \\ 'Center of Endocrinology and Diabetes, \\ Family Hospital, Da Nang, Vietnam; \\ ${ }^{2}$ Faculty of Public Health, Hue University \\ of Medicine and Pharmacy, Hue \\ University, Hue City, Vietnam; \\ ${ }^{3}$ Department of Internal Medicine, Hue \\ University of Medicine and Pharmacy, \\ Hue University, Hue City, Vietnam
}

Correspondence: Chi Van Le Department of Internal Medicine, Hue University of Medicine and Pharmacy, Hue University, No. 06 Ngo Quyen Str., Hue City, Vietnam

Tel +84 913426457

Email Ivanchi@hueuni.edu.vn
Background: Psychometric properties are regarded as one of the significant contributors related to diabetes treatment efficacy. Diabetes-related distress (DD) is one of the emotional burdens. The aims of this study were to investigate the prevalence of DD and to determine its associated factors among Vietnamese diabetic patients.

Methods: A cross-sectional study was conducted at a single medical center in the central of Vietnam. A total of 138 eligible DM outpatients were invited and a total of 112 patients who completed the questionnaire were utilized in this analysis using convenience sampling. DD was assessed using the diabetes distress scale (DDS). The participant's sociodemographic and clinical information was obtained through face-to-face interviews and medical records. Multivariate logistic regression was used to determine independent factors associated with the presence of DD. Results: Approximately, $12.5 \%$ of the patients experienced DD based on DDS selfadministered questionnaire. The rates of mild/moderate and high distress were $8.0 \%$ and $4.5 \%$, respectively. DD was found to be significantly higher in type $1 \mathrm{DM}(\mathrm{p}=0.04)$, insulin only in treatment regime $(p=0.04)$, physical inactivities $(p=0.02)$, times of mild hypoglycemia (time/month) $(\mathrm{p}=0.01)$, and fasting plasma glucose $(\mathrm{mmol} / \mathrm{l})(\mathrm{p}=0.04)$. The occurrence of distress among DM patients was negatively correlated with their age and amount of physical exercise. Meanwhile, poor $\mathrm{HbA} 1 \mathrm{c}$ control $(\mathrm{HbA} 1 \mathrm{c} \geq 7 \%)$ was associated with an increased occurrence of diabetes distress.

Conclusion: The findings of single medical center in Vietnam highlights that DD is prevalent among DM patients. It should be of marked concerns, particularly the type 1 diabetic patients, younger age, and poor glycemic control patients.

Keywords: diabetes mellitus, diabetes-related distress, diabetes distress scale

\section{Introduction}

Diabetes mellitus (DM) has recently regarded as one of the most common noncommunicable diseases affecting the global population. Around 9.3\% (463 million people) of the global adult population suffered from diabetes in $2019 .{ }^{1}$ It is one of the top 7 th leading global fatal diseases. ${ }^{2}$ Diabetes may lead to several short- and long-term health complications, including hypoglycemia, cardiovascular complications, neuropathy, nephropathy, amputation, and retinopathy which reduce patient's physical activities, labour efficiency, and life's quality. Recent guideline emphasizes the importance of screening, diagnosis, and management of emotional distress to achieve optimal outcomes, including improved self-care, glycemic control, reduced cardiovascular complications, and reduced all-cause mortality. ${ }^{3}$

Previous research has shown a bidirectional association between DM and psychological disorders such as stress and distress. ${ }^{4}$ Patients with diabetes experience 
psychosocial and emotional issues in response to these prolonged treatments, including worry about complications, fear of hypoglycemia, fatigue regarding poorly controlled blood glucose, and worthlessness. One of the emotional burdens is diabetes-related distress (DD) which is defined as a patient's concerns about diabetes mellitus, its management, the need for support, and access to healthcare. ${ }^{5}$ DD is rapidly rising as a result of the higher global burden of diabetes. The global prevalence of DD ranged from $8.8 \%$ to $65.5 \% .^{6-11}$ It may worsen the outcomes of DM. Poor or insufficient treatment of psychological disorders may cause inadequate self-care, impeds medication adherence, leading to poor glycemic control and increased morbidity and mortality. $^{12}$

Several self-report questionnaires were developed to investigate features and prevalence of DD, including the ATT39 (psychological adjustment to diabetes scale), ${ }^{13}$ problem areas in diabetes scale (PAID), ${ }^{14}$ and questionnaire on stress in patients with diabetes-revised (QSDR). ${ }^{15}$ These instruments aimed to recognize psychological reactions to diabetes and to be used in varied clinical and research settings. ${ }^{16-18}$

The diabetes distress scale (DDS), which surmounted the limitations of several previous instruments, such as the PAID, is commonly used for measuring DD. It was developed by Polonsky ${ }^{5}$ and validated for use in different nations. ${ }^{17,19-23}$ The DDS showed significantly stronger associations with DD and glycemic control and is recommended to be used academically and clinically. ${ }^{24}$

In Vietnam, DM imposes a significant burden in terms of individuals and health-care systems. A rapid increase of diabetes and prediabetes is often noticed in urban cities with the annual rising rate of about $6.23 \%$, and $16.17 \%$, respectively. $^{25}$ This imposed a further burden of DD that will result in a more severe state of the diseases. Therefore, the risk of distress among the patients with diabetes should be figured out along with clinical treatment.

In this study, we aimed to investigate the prevalence of DD and to determine its associated factors among Vietnamese DM patients.

\section{Methods}

\section{Study Designs and Sampling}

A cross-sectional study was conducted from February 2020 to March 2020 at the Center of Endocrinology and Diabetes, Family Hospital, Da Nang, Vietnam. We invited patients to enrol in this study if they met the following inclusion criteria: 1) Diagnosed with DM according to American Diabetes Association guidelines in 2020 at least 3 months ago; ${ }^{26}$ 2)agreed to participate voluntarily 3 ) be able to answer the questionnaire completely; 4) did not have any acute and serious illness. With the aim of estimating the prevalence of DD in patients with diabetes, we applied a formula for a proportion with a specified the relative precision to calculate the sample size of this study. With a confidence interval of 0.95 , a relative precision of 0.05 , and the expected proportion of distress among patients with diabetes at $8.9 \%$ (according to the previous study in Thailand $^{27}$ ). A size of the sample of 125 participants would suffice. ${ }^{28}$ However, a refusal rate was predicted to be $10 \%$, the final sample size was decided to 138 .

One hundred and thirty-eight eligible DM outpatients were identified at the Da Nang Family Hospital and invited to participate in this study using convenience sampling. The interviews with patients were conducted face-to -face by well-trained nurses in the same hospital. Sociodemographic and clinical information was collected by using a structured questionnaire from patients and electronic medical records system.

\section{Ethical Approval}

This study was conducted in accordance with the Declaration of Helsinki. The study protocol was approved by the institutional review board of the Danang Family Hospital (number: 12.01-30,303). With the approval, potential patients were invited to participate in this study. Prior to the interviews, the participants were informed of this study via an information sheet; they also received detailed information from the interviewers, following which they signed the consent form. They could withdraw at any time from the research without affecting their current treatment. Their information was kept confidential and used for research purposes only.

\section{Data Measurements}

\section{Sociodemographic Characteristics}

In this study, sociodemographic information included age (continuous variable, grouped: $>60$ years and $\leq 60$ years), gender (categorical variable: male and female), occupation (categorical variable: retirement, officers, self-employed, and others), marital status (categorical variable: single, married, and widow/divorced), residence (categorical variable: urban areas and others), and educational background (categorical variable: literate, primary school (grade 1-5), 
secondary/high school (grade 6-12), and vocational/ college).

\section{Clinical Characteristics}

Clinical information included the type of diabetes (categorical variable: type 1 , type 2 , and others), duration of diabetes (categorical variable: $<5$ years, 5-10 years, and $>10$ years $)$, blood pressure $(\mathrm{mmHg})$, body mass index $(\mathrm{kg} /$ $\mathrm{m}^{2}$ ), antihyperglycemic medications (categorical variable: oral antidiabetic drugs (OAD), OAD+insulin, and insulin only), waist $(\mathrm{cm})$, hypoglycemia periods (categorical variable: mild, moderate, and severity), fasting plasma glucose (mmol/l), lipid profile (mmol/l), and HbAlc (\%).

\section{The Diabetes Distress Scale (DDS)}

The DDS consists of 17 items used to measure DD and 4 domains (emotional burden, physician care, disease management, and interpersonal support). Each dimension was rated on a 6 -point Likert scale $(1=$ not a problem; $2=$ a slight problem; $3=$ a moderate problem; $4=$ somewhat serious problem; $5=$ a serious problem; and $6=$ a very serious problem). ${ }^{5,6}$ The total mean item score was calculated by dividing the total score by 17 , and each domainspecific subscale was calculated by dividing the total scores of the subscale by the number of questions associated with it. With a possible range of 1 to 6 , a high score indicates a higher distress level. The overall DDS and each sub-component scale were evaluated using the following: a mean score of $<2$, considering as "no distress"; a mean score between 2 and 2.9, considering as "moderate distress"; and a mean score $\geq 3$, considering as "high distress". The DDS were translated into Vietnamese version and validated in Vietnamese patients by Thinh et al with Cronbach's alpha coefficient was $0.76-0.93$ for each subscale and 0.94 for the overall. ${ }^{29}$

\section{Data Analysis}

All data analyses were performed using SPSS software version 20.0 for Windows. Kruskal-Wallis test, $t$-test, and Chi-squared test were applied to determine the difference of characteristics between no distress and having distress. A p-value $<0.05$ was considered statistical significance. Multivariate logistic regression was employed to identify the risk factors associated with DD in participants. A stepwise backward selection strategy, which started with a full model, was used with $\mathrm{p}<0.2$ as a threshold of the log-likelihood test to remove the variables to construct the reduced multivariate models and to choose the best model for data analysis.

\section{Results}

A total of 112 patients completed the questionnaire were utilized in this analysis, given participation rate $81.16 \%$ (15 participants withdrew and 11 patients did not have results of $\mathrm{HbAlc}$ test).

Table 1 shows the demographic characteristics of participants in this study. Mean age of patients was 53.8 (SD, $11.9)$ years. The majority of gender were males $(52.7 \%)$, having a secondary and high school education or above $(79.4 \%)$, officers or self-employed $(58.1 \%)$, living with relatives $(99.1 \%)$, and living in urban areas $(85.7 \%)$. $92.9 \%$ of the patient was type 2 DM.

The mean of $\mathrm{HbA} 1 \mathrm{C}$ and fasting plasma glucose were $7.2 \%$ (SD, 1.5) and $7.5 \mathrm{mmol} / \mathrm{l}(\mathrm{SD}, 2.6)$, respectively. The prevalence of overweight and obesity was $67.0 \%$, of dyslipidemia was $83.9 \%$, and android obesity was $58.0 \%$.

Table 2 reveals the DD and its dimensions. About $87.5 \%$ of the patients did not experience DD based on DDS self-administered questionnaire. Meanwhile, the rates of $\mathrm{mild} /$ moderate and high distress were $8.0 \%$ and $4.5 \%$, respectively. The emotional burden (EB) subcomponent had the greatest moderate/high level of distress (36.6\%). Physician distress (PD) had the least moderate/ high level of distress $(7.2 \%)$.

Table 3 presents the prevalence of DD and its by demographic characteristics. There was a significant difference in age between 2 groups of DD $(p<0.05)$. Other factors of sociodemographic were not significantly different between those with and without DD ( $>00.05)$.

Table 4 gives information on the prevalence of DD in accordance with distribution of clinical characteristics. DD was found to be significantly higher in type $1 \mathrm{DM}$ $(p=0.04)$, insulin only in treatment regime $(p=0.04)$, physical inactivities $(\mathrm{p}=0.02)$, times of mild hypoglycemia (time/month $) \quad(p=0.01)$, and fasting plasma glucose $(\mathrm{mmol} / \mathrm{l})(\mathrm{p}=0.04)$.

The associated factors with DD extracted from multivariate logistic regression are shown in Table 5. The model confirmed that the occurrence of distress among DM patients was negatively correlated with their age and quantity of physical activities in an odds ratio of $95 \%$ confident interval (CI): 0.92 (0.87-0.97), 0.19 (0.05-0.75), respectively. Whereas poor $\mathrm{HbAlc}$ control was associated with increasing prevalence of diabetes distress in an odds ratio of 95\% CI: 5.49 (1.26-24.0). 
Table I Demographic Characteristics of DM Participants in This Study

\begin{tabular}{|c|c|c|}
\hline \multirow[t]{2}{*}{ Characteristics } & \multicolumn{2}{|c|}{ Total $(n=\mid 12)$} \\
\hline & $\mathbf{n}$ & $\%$ \\
\hline \multicolumn{3}{|l|}{ Gender } \\
\hline Female & 53 & 47.3 \\
\hline Male & 59 & 52.7 \\
\hline \multicolumn{3}{|l|}{ Age group } \\
\hline$>60$ & 29 & 25.9 \\
\hline$\leq 60$ & 83 & 74.1 \\
\hline \multicolumn{3}{|l|}{ Occupation } \\
\hline Retirement & 23 & 20.5 \\
\hline Officers & 21 & 18.8 \\
\hline Self-employed & 44 & 39.3 \\
\hline Others & 24 & 21.4 \\
\hline \multicolumn{3}{|l|}{ Living area } \\
\hline Urban areas & 96 & 85.7 \\
\hline Others & 16 & 14.3 \\
\hline \multicolumn{3}{|l|}{ Educational status } \\
\hline Literate & 6 & 5.4 \\
\hline Primary school & 17 & 15.2 \\
\hline Secondary/high school & 51 & 45.5 \\
\hline Vocational/college & 38 & 33.9 \\
\hline \multicolumn{3}{|l|}{ Marital status } \\
\hline Single & 9 & 8.0 \\
\hline Married & 90 & 80.4 \\
\hline Widow/Divorced & 13 & 11.6 \\
\hline \multicolumn{3}{|l|}{ Living arrangement } \\
\hline Living alone & I & 0.9 \\
\hline Living with relatives & 111 & 99.1 \\
\hline \multirow[t]{2}{*}{ Age, year } & Mean & SD \\
\hline & 53.8 & 11.9 \\
\hline
\end{tabular}

These 3 variables in our final model that have explained about $32.6 \%$ of change in DD $\left(\chi^{2}=21.198\right.$; $\mathrm{p}$-value $\left.=0.000\right)$.

\section{Discussion}

Our study contributes empirical insights into the mental health aspect of patients with diabetes at the primary care level in the central area of Vietnam. It highlights a significant rate of distress among DM patients marked at $12.5 \%$. Of which $8.0 \%$ of them had mild to moderate distress, and $4.5 \%$ had high distress. The greatest moderatehigh level of distress belonged to the EB sub-component $(36.6 \%)$. PD had the least moderate-high level of distress (7.2\%). Furthermore, age, physical activities, and poor $\mathrm{HbA} 1 \mathrm{C}$ control were found to be predictors of DD.

In comparison of prevalence of DD with other regions, our results indicate lower than those reported in China $(42.15 \%){ }^{22}$ Bangladesh (48.5\%), ${ }^{11}$ Malaysia (49.2\%), ${ }^{21}$ the United States (US) $(51.3 \%){ }^{30}$ and Iran $(63.7 \%) .^{31}$ These differences of DD prevalence could be explained by sample size, health-care system, care setting, sociodemographic variables (education level and living arrangement), as well as health conditions (the type of diabetes, HbA1c level, and co-morbidity). ${ }^{21,32,33}$ We enrolled in the sample from the primary care hospital, where patients having a good health status and high satisfaction rates. ${ }^{34}$ Our findings also are in line with those of the studies conducted in Germany and the Netherlands, where patients with diabetes treated in a secondary and tertiary hospital had higher DD prevalence than in those treated in a primary hospital. ${ }^{35,36}$

Our findings revealed that the type of diabetes had a significant relationship with DD. About $50 \%$ of type 1 DM patients had distress, while only $9.6 \%$ of type 2 patients with diabetes experienced distress. It was explained by certain causal factors such as emotional burden and nonpsychiatric emotional reactions to the onset, course, management by insulin injection, glucose level, complications of type 1 diabetes, and the fear of hypoglycemia. ${ }^{37,38}$ In addition, the current study's findings indicated that younger age

Table 2 Diabetes Distress and Internal Consistency Among Diabetes Mellitus Patients

\begin{tabular}{|l|l|l|l|l|l|l|l|l|l|}
\hline \multirow{2}{*}{ Subscales } & \multicolumn{2}{l}{ Mean } & \multicolumn{2}{l}{ No Distress } & \multicolumn{2}{l|}{ Moderate Distress } & \multicolumn{2}{l|}{ High Distress } \\
\cline { 2 - 13 } & $\mathbf{X} \pm$ SD & Min & Max & $\mathbf{n}$ & $\%$ & $\mathbf{n}$ & $\%$ & $\mathbf{n}$ & $\%$ \\
\hline Emotional burden (EB) & $1.8 \pm 0.8$ & $\mathrm{I}$ & 4.8 & 71 & 63.4 & 29 & 25.9 & 12 & 10.7 \\
\hline Physician distress (PD) & $1.3 \pm 0.9$ & $\mathrm{I}$ & 6 & 104 & 92.9 & 2 & 1.8 & 6 & 5.4 \\
\hline Regimen distress (RD) & $1.5 \pm 0.7$ & $\mathrm{I}$ & 4.6 & 93 & 83.0 & 14 & 12.5 & 5 & 4.5 \\
\hline Interpersonal distress (ID) & $1.2 \pm 0.6$ & $\mathrm{I}$ & 5.7 & 101 & 90.2 & 9 & 8.0 & 2 & 1.8 \\
\hline Total DDS & $1.5 \pm 0.6$ & $\mathrm{I}$ & 4.8 & 98 & 87.5 & 9 & 8.0 & 5 \\
\hline
\end{tabular}


Table 3 Differences Between Patients with and without Diabetes-Related Distress by Sociodemographic Factors

\begin{tabular}{|c|c|c|c|c|c|c|}
\hline \multirow[t]{2}{*}{ Characteristics } & \multirow{2}{*}{$\begin{array}{l}\text { Total }(n=|| 2) \\
n\end{array}$} & \multicolumn{2}{|c|}{ Diabetes-Related Distress $(n=14)$} & \multicolumn{2}{|c|}{ No Diabetes-Related Distress $(\mathrm{n}=98)$} & \multirow[t]{2}{*}{ p-value } \\
\hline & & $\mathbf{n}$ & $\%$ & $\mathbf{n}$ & $\%$ & \\
\hline $\begin{array}{l}\text { Gender } \\
\text { Female } \\
\text { Male }\end{array}$ & $\begin{array}{l}53 \\
59\end{array}$ & $\begin{array}{l}5 \\
9\end{array}$ & $\begin{array}{l}9.4 \\
15.3\end{array}$ & $\begin{array}{l}48 \\
50\end{array}$ & $\begin{array}{l}90.6 \\
84.7\end{array}$ & 0.40 \\
\hline $\begin{array}{l}\text { Age group } \\
>60 \\
\leq 60\end{array}$ & $\begin{array}{l}29 \\
83\end{array}$ & $\begin{array}{l}2 \\
12\end{array}$ & $\begin{array}{l}6.9 \\
14.5\end{array}$ & $\begin{array}{l}27 \\
71\end{array}$ & $\begin{array}{l}93.1 \\
85.5\end{array}$ & 0.51 \\
\hline $\begin{array}{l}\text { Occupation } \\
\text { Retirement } \\
\text { Officers } \\
\text { Self-employed } \\
\text { Others }\end{array}$ & $\begin{array}{l}23 \\
21 \\
44 \\
24\end{array}$ & $\begin{array}{l}3 \\
3 \\
6 \\
2\end{array}$ & $\begin{array}{l}13.0 \\
14.3 \\
13.6 \\
8.3\end{array}$ & $\begin{array}{l}20 \\
18 \\
38 \\
22\end{array}$ & $\begin{array}{l}87.0 \\
85.7 \\
86.4 \\
91.7\end{array}$ & 0.92 \\
\hline $\begin{array}{l}\text { Living area } \\
\text { Urban areas } \\
\text { Others }\end{array}$ & $\begin{array}{l}96 \\
16\end{array}$ & $\begin{array}{l}11 \\
3\end{array}$ & $\begin{array}{l}11.5 \\
18.7\end{array}$ & $\begin{array}{l}85 \\
13\end{array}$ & $\begin{array}{l}88.5 \\
81.3\end{array}$ & 0.49 \\
\hline $\begin{array}{l}\text { Educational status } \\
\text { Literate } \\
\text { Primary school } \\
\text { Secondary/high school } \\
\text { Vocational/college }\end{array}$ & $\begin{array}{l}6 \\
17 \\
51 \\
38\end{array}$ & $\begin{array}{l}0 \\
2 \\
6 \\
6\end{array}$ & $\begin{array}{l}0 \\
11.8 \\
11.8 \\
15.8\end{array}$ & $\begin{array}{l}6 \\
15 \\
45 \\
32\end{array}$ & $\begin{array}{l}100 \\
88.2 \\
88.2 \\
84.2\end{array}$ & 0.73 \\
\hline $\begin{array}{l}\text { Marital status } \\
\text { Single } \\
\text { Married } \\
\text { Widow/divorced }\end{array}$ & $\begin{array}{l}9 \\
90 \\
13\end{array}$ & $\begin{array}{l}2 \\
12 \\
0\end{array}$ & $\begin{array}{l}22.2 \\
13.3 \\
0\end{array}$ & $\begin{array}{l}7 \\
78 \\
13\end{array}$ & $\begin{array}{l}77.8 \\
86.7 \\
100\end{array}$ & 0.26 \\
\hline $\begin{array}{l}\text { Living arrangement } \\
\text { Living alone } \\
\text { Living with relatives }\end{array}$ & $\begin{array}{l}1 \\
111\end{array}$ & $\begin{array}{l}0 \\
14\end{array}$ & $\begin{array}{l}0 \\
12.6\end{array}$ & $\begin{array}{l}1 \\
97\end{array}$ & $\begin{array}{l}100 \\
87.4\end{array}$ & 1.0 \\
\hline
\end{tabular}

was significantly related to higher distress scores. Furthermore, a higher target of diabetic control in younger patients with diabetes, additional stressors of family responsibilities, work, and financial challenges affected them negatively. Therefore, managing diabetes may be contributing to their already high distress level. ${ }^{39}$

Notably, it was found from the current study that patients treated by injecting insulin only had higher distress than those treated with OAD or OAD plus insulin. They were $33.3 \%$, $11.5 \%$ and $4.5 \%$, respectively. When injecting insulin at least 2 times per day, patients might experience pain, feeling inconvenient, being frequently hospitalized, reducing the quality of life, and fear of hypoglycemia. ${ }^{40}$ From this result, insulintreated patients with diabetes should be cautioned in mental health care. Additionally, there was a significant relationship between the quantity of physical activities, means of fasting glucose, and distress. Patients with a good fasting glucose level might be satisfied with physicians and current treatment regimes. Therefore, they experienced less distress. However, age group, sex, marital status, occupation, residence, educational background, presence of co-morbidity (hypertension, android obesity, dyslipidemia), living arrangement, duration of DM, BMI (low/normal, overweight/obese), and HbA1c level $(<7 \%, \geq 7 \%$ ) were not significantly associated with the level of total diabetes distress.

From the results of the multivariate logistic regression model, it can be concluded that age and sufficient physical activities were negatively associated with the occurrence of distress among DM patients. While poor HbA1c control (HbA1c $\geq 7 \%$ ) increased 5.49 times of diabetes distress. These findings are consistent with some studies in Japan, ${ }^{41}$ the US, ${ }^{6}$ and Thailand ${ }^{17}$ that showed the positive association between $\mathrm{HbA} 1 \mathrm{c}$ control and DD. However, it was reported in previous studies that psychological changes in patients with diabetes 
Table 4 Clinical Characteristics and Prevalence of DD by Its Information Among Patients with Diabetes

\begin{tabular}{|c|c|c|c|c|c|c|c|}
\hline \multirow[t]{2}{*}{ Characteristics } & \multicolumn{2}{|c|}{ Total $(n=|| 2)$} & \multicolumn{2}{|c|}{$\begin{array}{l}\text { Diabetes-Related Distress } \\
(n=\mid 4)\end{array}$} & \multicolumn{2}{|c|}{$\begin{array}{l}\text { No Diabetes-Related } \\
\text { Distress }(n=98)\end{array}$} & \multirow[t]{2}{*}{ p-value } \\
\hline & $\mathbf{n}$ & $\%$ & $\mathbf{n}$ & $\%$ & $\mathbf{n}$ & $\%$ & \\
\hline \multicolumn{8}{|l|}{ Type of diabetes } \\
\hline Type I & 6 & 5.4 & 3 & 50.0 & 3 & 50.0 & 0.04 \\
\hline Type 2 & 104 & 92.9 & 10 & 9.6 & 94 & 90.4 & \\
\hline Others & 2 & 1.8 & 1 & 50.0 & I & 50.0 & \\
\hline \multicolumn{8}{|l|}{ BMI } \\
\hline Low/normal & 37 & 33.0 & 5 & 13.5 & 32 & 86.5 & 1.0 \\
\hline Overweight/Obese & 75 & 67.0 & 9 & 12 & 66 & 88.0 & \\
\hline \multicolumn{8}{|l|}{$\begin{array}{l}\text { Duration of diabetes } \\
\text { (years) }\end{array}$} \\
\hline$<5$ & 63 & 56.3 & 8 & 12.7 & 55 & 87.3 & 0.46 \\
\hline $5-10$ & 40 & 35.7 & 6 & 15.0 & 34 & 85.0 & \\
\hline$>10$ & 9 & 8.0 & 0 & 0 & 9 & 100 & \\
\hline \multicolumn{8}{|c|}{ Current treatment regime } \\
\hline OAD & 78 & 69.6 & 9 & 11.5 & 69 & 88.5 & 0.04 \\
\hline OAD+ insulin & 22 & 19.6 & 1 & 4.5 & 21 & 95.5 & \\
\hline Insulin only & 12 & 10.7 & 4 & 33.3 & 8 & 66.7 & \\
\hline \multicolumn{8}{|l|}{ Hypertension } \\
\hline Yes & 32 & 28.6 & 4 & 12.5 & 28 & 87.5 & 1.0 \\
\hline No & 80 & 71.4 & 10 & 12.5 & 70 & 87.5 & \\
\hline \multicolumn{8}{|l|}{ Android obesity } \\
\hline Yes & 65 & 58.0 & 9 & 13.8 & 56 & 86.2 & 0.7 \\
\hline No & 47 & 42.0 & 5 & 10.6 & 42 & 89.4 & \\
\hline \multicolumn{8}{|l|}{ Medical nutrition } \\
\hline Yes & 62 & 55.4 & 9 & 14.5 & 53 & 85.5 & 0.57 \\
\hline No & 50 & 44.6 & 5 & 10.0 & 45 & 90.0 & \\
\hline \multicolumn{8}{|c|}{ Sufficient physical activity } \\
\hline Yes & 92 & 82.1 & 8 & 8.7 & 84 & 91.3 & 0.02 \\
\hline No & 20 & 17.9 & 6 & 30.0 & 14 & 70.0 & \\
\hline \multicolumn{8}{|l|}{ HbAlc (\%) } \\
\hline$<7$ & 59 & 52.7 & 4 & 6.8 & 55 & 93.2 & 0.053 \\
\hline$\geq 7$ & 53 & 47.3 & 10 & 18.9 & 43 & 81.1 & \\
\hline \multicolumn{8}{|c|}{$\begin{array}{l}\text { Fasting plasma glucose } \\
\text { control }\end{array}$} \\
\hline Good & 63 & 56.8 & 4 & 6.3 & 59 & 93.7 & 0.40 \\
\hline Not good & 48 & 43.2 & 10 & 20.8 & 38 & 79.2 & \\
\hline \multicolumn{8}{|l|}{ Dyslipidemia } \\
\hline Yes & 94 & 83.9 & 12 & 12.8 & 82 & 87.2 & 1.0 \\
\hline No & 18 & 16.1 & 2 & 11.1 & 16 & 88.9 & \\
\hline
\end{tabular}

(Continued) 
Table 4 (Continued).

\begin{tabular}{|c|c|c|c|c|c|c|c|}
\hline \multirow[t]{2}{*}{ Characteristics } & \multicolumn{2}{|c|}{ Total $(n=|| 2)$} & \multicolumn{2}{|c|}{$\begin{array}{l}\text { Diabetes-Related Distress } \\
(n=14)\end{array}$} & \multicolumn{2}{|c|}{$\begin{array}{l}\text { No Diabetes-Related } \\
\text { Distress }(n=98)\end{array}$} & \multirow[t]{2}{*}{ p-value } \\
\hline & $\mathbf{n}$ & $\%$ & $\mathbf{n}$ & $\%$ & $\mathbf{n}$ & $\%$ & \\
\hline & $\begin{array}{l}\text { Mean } \\
\text { (median) }\end{array}$ & SD & $\begin{array}{l}\text { Mean } \\
\text { (median) }\end{array}$ & SD & $\begin{array}{l}\text { Mean } \\
\text { (median) }\end{array}$ & SD & \\
\hline \multicolumn{8}{|l|}{$\begin{array}{l}\text { Time of hypoglycemia } \\
\text { (time/month) }\end{array}$} \\
\hline Mild & $0.9(0.0)$ & 1.6 & $2.3(1.5)$ & 2.7 & $0.7(0.0)$ & 1.3 & 0.001 \\
\hline Moderate & $0.4(0.0)$ & 1.5 & I.3 (0.0) & 3.7 & $0.2(0.0)$ & 0.8 & 0.15 \\
\hline Severity & $0.04(0.0)$ & 0.28 & $0.14(0.0)$ & 0.5 & $0.03(0.0)$ & 0.22 & 0.26 \\
\hline HbAlc (\%) & 7.2 & 1.5 & 7.7 & 1.4 & 7.1 & 1.5 & 0.15 \\
\hline $\begin{array}{l}\text { Fasting plasma glucose } \\
(\mathrm{mmol} / \mathrm{l})\end{array}$ & 7.5 & 2.6 & 8.9 & 3.4 & 7.3 & 2.4 & 0.04 \\
\hline
\end{tabular}

Table 5 Predictors of Diabetes-Related Distress Among DM Patients: Multivariate Logistic Regression

\begin{tabular}{|c|c|c|c|c|c|}
\hline \multirow{3}{*}{$\begin{array}{l}\text { Characteristics } \\
\text { Age (year) }\end{array}$} & \multicolumn{5}{|c|}{ Having Diabetes Distress (Yes vs No) } \\
\hline & \multirow{2}{*}{$\frac{\text { B }}{-0.08}$} & \multirow{2}{*}{$\begin{array}{l}\text { OR } \\
0.92\end{array}$} & \multicolumn{2}{|c|}{$95 \% \mathrm{Cl}$} & \multirow{2}{*}{$\begin{array}{l}\text { p-value } \\
0.01\end{array}$} \\
\hline & & & 0.87 & 0.97 & \\
\hline Sufficient physical activity (yes) & -1.65 & 0.19 & 0.05 & 0.75 & 0.017 \\
\hline $\mathrm{HbAlc}(\geq 7 \%)$ & 1.7 & 5.49 & 1.26 & 24.0 & 0.024 \\
\hline \multirow[t]{2}{*}{ Constant } & 2.51 & 12.36 & & & \\
\hline & \multicolumn{5}{|c|}{$\chi^{2}=21.198 ; p$-value $=0.000 ; \mathrm{R}^{2}=0.326$} \\
\hline
\end{tabular}

Note: Adjusted model included all variables: age, sufficient physical activity, HbAlc, waist, times of mild hypoglycemic periods.

exerted an impact on metabolic control and complications significantly. ${ }^{17}$ Therefore, a bidirectional impact of glycemic control and psychological disorders should be of concern.

The strengths of our study include the application of a validated Vietnamese language of DDS in DM patients in the primary setting. The study also contributes more insights into current situation of DD among Vietnamese patients. However, there exist a number of limitations in the current study, which maps out directions for further research. First, this is a cross-sectional study with the convenience sampling method in a single hospital, which may not represent the whole picture of DD among Vietnamese patients throughout the nation. Another shortcoming is that the causal relationships between the occurrence of distress and DM, as well as other covariables could not be established due to the limitation of the cross-sectional study. Third, other potential variables, including patient training of glycemic control, history of mental health, medical insurance, and cost of treatment were not identified in this study as factors affecting the DD rates among patients with diabetes.

\section{Conclusion}

The findings of single medical center in Vietnam highlights that DD is prevalent among DM patients, requiring early screening and giving psychiatric care service to this population promptly, particularly type 1 diabetic patients, younger age, and poor glycemic control patients.

\section{Abbreviations}

ATT39, psychological adjustment to diabetes scale; CI, confident interval; EB, emotional burden; DD, diabetes distress; DDS, diabetes distress scale; DM, diabetes mellitus; PD, physician distress; PAID, problem areas in 
diabetes scale; QSD-R, questionnaire on stress in patients with diabetes-revised; OAD, oral antidiabetic drugs; SD, standard deviation; US, United States.

\section{Data Sharing Statement}

Availability of data and materials supporting our findings will be shared upon request.

\section{Consent to Participate}

Written informed consent form was given to patients.

\section{Acknowledgments}

The authors would like to thank the patients who agreed to participate in this cohort study. Our sincere gratitude is expressed to Dr. Thinh and his colleagues for the Vietnamese version DDS17.

\section{Author Contributions}

All authors contributed to data analysis, drafting or revising the article, have agreed on the journal to which the article will be submitted, gave final approval of the version to be published, and agree to be accountable for all aspects of the work.

\section{Funding}

The research project was financially supported by Danang Family Hospital, Da Nang, Vietnam.

\section{Disclosure}

The authors report no conflicts of interest for this work.

\section{References}

1. Saeedi P, Petersohn I, Salpea P, et al. Global and regional diabetes prevalence estimates for 2019 and projections for 2030 and 2045: results from the international diabetes federation diabetes atlas. Diabetes Res Clin Pract. 2019;157:107843.

2. World Health Organization. The top 10 causes of death: world Health Organization. World Health Organization Fact Sheets. 2017. Available from: http://www.who.int/mediacentre/factsheets/fs310/en. Accessed December 3, 2020.

3. American Diabetes Association. Standards of medical care in diabetes - 2017 abridged for primary care providers. Clin Diabetes. 2017;35 (1):5-26. doi:10.2337/cd16-0067

4. Conversano C. Common psychological factors in chronic diseases. Front Psychol. 2019;10:2727. doi:10.3389/fpsyg.2019.02727

5. Polonsky WH, Fisher L, Earles J, et al. Assessing psychosocial distress in diabetes: development of the diabetes distress scale. Diabetes Care. 2005;28(3):626-631. doi:10.2337/diacare.28.3.626

6. Fisher L, Hessler DM, Polonsky WH, et al. When is diabetes distress clinically meaningful?: establishing cut points for the diabetes distress scale. Diabetes Care. 2012;35(2):259-264. doi:10.2337/dc11-1572

7. Aikens JE. Prospective associations between emotional distress and poor outcomes in type 2 diabetes. Diabetes Care. 2012;35 (12):2472-2478. doi:10.2337/dc12-0181
8. Faber-Wildeboer AT, van Os-Medendorp H, Kooy A, Sol-De Rijk B. Prevalence and risk factors of depression and diabetes-related emotional distress in patients with type 2 diabetes: a cross-sectional study. J Nurs Educ Pract. 2013;3(6):61.

9. Zhang J, Xu CP, Wu HX, et al. Comparative study of the influence of diabetes distress and depression on treatment adherence in Chinese patients with type 2 diabetes: a cross-sectional survey in the People's Republic of China. Neuropsychiatr Dis Treat. 2013;9:1289.

10. Baradaran HR, Mirghorbani SM, Javanbakht A, Yadollahi Z, Khamseh ME. Diabetes distress and its association with depression in patients with type 2 diabetes in Iran. Int J Prev Med. 2013;4 (5):580.

11. Islam M, Karim MR, Habib SH, et al. Diabetes distress among type 2 diabetic patients. Int $J$ Med Biomed Res. 2013;2(2):113-124. doi:10.14194/ijmbr.224

12. Gonzalez JS, Tanenbaum ML, Commissariat PV. Psychosocial factors in medication adherence and diabetes self-management: implications for research and practice.. Am Psychol. 2016;71(7):539-551. doi:10.1037/a0040388

13. Dunn SM, Smartt HH, Beeney LJ, Turtle JR. Measurement of emotional adjustment in diabetic patients: validity and reliability of ATT39. Diabetes Care. 1986;9(5):480-489.

14. Polonsky WH, Anderson BJ, Lohrer PA, et al. Assessment of diabetes-related distress. Diabetes Care. 1995;18(6):754-760. doi:10.2337/diacare.18.6.754

15. Herschbach P, Duran G, Waadt S, et al. Psychometric properties of the Questionnaire on Stress in patients with Diabetes-Revised (QSD-R). Health Psychol. 1997;16(2):171. doi:10.1037/02786133.16.2.171

16. Lerman-Garber I, Barrón-Uribe C, Calzada-León R, et al. Emotional dysfunction associated with diabetes in Mexican adolescents and young adults with type-1 diabetes. Salud Publica Mex. 2003;45 (1):13-18. doi:10.1590/S0036-36342003000100002

17. Tunsuchart K, Lerttrakarnnon P, Srithanaviboonchai K, et al. Type 2 diabetes mellitus related distress in Thailand. Int $J$ Environ Res Public Health. 2020;17(7):2329. doi:10.3390/ijerph17072329

18. Farm BAS, Perwitasari DA, Thobari JA, et al. Translation, revision, and validation of the diabetes distress scale for Indonesian type 2 diabetic outpatients with various types of complications. Value Health Reg Issues. 2017;12:63-73. doi:10.1016/j.vhri.2017.03.010

19. Darawad MW, Hammad S, Samarkandi OA, et al. Evaluating the psychometric properties of the Arabic version of the diabetes distress scale. J Psychosoc Nurs Ment Health Serv. 2017;55(9):43-51. doi:10.3928/02793695-20170818-12

20. Silveira MSVM, Bovi TG, Oliveira PF, et al. Translation and cultural adaptation into Brazilian culture of type 1 diabetes distress scale. Diabetol Metab Syndr. 2017;9(1):61. doi:10.1186/s13098-017-0260-y

21. Chew B-H, Vos R, Mohd-Sidik S, et al. Diabetes-related distress, depression and distress-depression among adults with type 2 diabetes mellitus in Malaysia. PLoS One. 2016;11(3):e0152095. doi:10.1371/ journal.pone.0152095

22. Zhou H, Zhu J, Liu L, et al. Diabetes-related distress and its associated factors among patients with type 2 diabetes mellitus in China. Psychiatry Res. 2017;252:45-50. doi:10.1016/j.psychres.2017.02.049

23. Martinez-Vega IP, Doubova SV, Aguirre-Hernandez R, et al. Adaptation and validation of the distress scale for Mexican patients with type 2 diabetes and hypertension: a cross-sectional survey. $B M J$ Open. 2016;6(3):e009723. doi:10.1136/bmjopen-2015-009723

24. Lee AA, Piette JD, Heisler M, Rosland AM. Diabetes distress and glycemic control: the buffering effect of autonomy support from important family members and friends. Diabetes care. 2018;41 (6): 1157-1163.

25. Ton TT, Tran Anhthingoc, Do IT, et al. Examining prevalence trends of pre-diabetes and diabetes and associated risk factors in Vietnamese adults. Epidemiol Health. 2020;42:e2020029. doi:10.4178/epih. e2020029 
26. American Diabetes Association. Classification and diagnosis of diabetes: standards of medical care in diabetes-2020. Diabetes Care. 2020;43(Suppl Supplement 1):S14. doi:10.2337/dc20-S002

27. Thanakwang K, Thinganjana W, Konggumnerd R. Psychometric properties of the Thai version of the diabetes distress scale in diabetic seniors. Clin Interv Aging. 2014;9:1353-1361. doi:10.2147/CIA.S67200

28. Dhand NK, Khatkar MS. Statulator: an online statistical calculator. Sample size calculator for estimating a single proportion. 2014 [cited November 12, 2020]. Available from: http://statulator.com/ SampleSize/ss1P.html. Accessed December 3, 2020.

29. Thinh O.P, Huynh A, Do T, et al. Translation and cross-cultural adaptation of the Vietnamese version of the diabetes distress scale. MedpharmRes. 2018;2(3):5-11. doi:10.32895/UMP.MPR.2.3.5

30. Fisher L, Mullan JT, Arean P, et al. Diabetes distress but not clinical depression or depressive symptoms is associated with glycemic control in both cross-sectional and longitudinal analyses. Diabetes Care. 2010;33(1):23-28. doi:10.2337/dc09-1238

31. Parsa S, Aghamohammadi M, Abazari M. Diabetes distress and its clinical determinants in patients with type II diabetes. Diabetes Metab Syndr. 2019;13(2):1275-1279. doi:10.1016/j.dsx.2019.02.007

32. Aljuaid MO, Almutairi AM, Assiri MA, et al. Diabetes-related distress assessment among type 2 diabetes patients. J Diabetes Res. 2018;2018:7328128. doi:10.1155/2018/7328128

33. Tol A, Baghbanian A, Sharifirad G, et al. Assessment of diabetic distress and disease related factors in patients with type 2 diabetes in Isfahan: a way to tailor an effective intervention planning in Isfahan-Iran. J Diabetes Metab Disord. 2012;11(1):20. doi:10.1186/2251-6581-11-20

34. Hu R, Liao Y, Du Z, et al. Types of health care facilities and the quality of primary care: a study of characteristics and experiences of Chinese patients in Guangdong Province, China. BMC Health Serv Res. 2016;16(1):335. doi:10.1186/s12913-016-1604-2
35. Kuniss N, Rechtacek T, Kloos C, et al. Diabetes-related burden and distress in people with diabetes mellitus at primary care level in Germany. Acta Diabetol. 2017;54(5):471-478. doi:10.1007/s00592-0170972-3

36. Stoop CH, Nefs G, Pop VJ, et al. Diabetes-specific emotional distress in people with Type 2 diabetes: a comparison between primary and secondary care. Diabet Med. 2014;31(10):1252-1259.

37. Joensen L, Tapager I, Willaing IJDM. Diabetes distress in type 1 diabetes-a new measurement fit for purpose. Diabet Med. 2013;30 (9):1132-1139. doi:10.1111/dme.12241

38. Polonsky WH, Davis CL, Jacobson AM, Anderson BJ. Correlates of hypoglycemic fear in type I and type II diabetes mellitus. Health Psychol. 1992;11(3):199.

39. Wardian J, Sun F. Factors associated with diabetes-related distress: implications for diabetes self-management. Soc Work Health Care. 2014;53(4):364-381. doi:10.1080/00981389.2014.884038

40. Lee HJ, Jang J, Lee SA, et al. Association between the type of diabetes treatment and depressive symptoms among patients with diabetes: a Cross-Sectional Study of Korea community health surveys data, 2011-2016. Int J Environ Res Public Health. 2019;16(22):4441. doi:10.3390/ijerph16224441

41. Tsujii S, Hayashino Y, Ishii H, Diabetes Distress and Care Registry at Tenri Study Group. Diabetes distress, but not depressive symptoms, is associated with glycaemic control among Japanese patients with type 2 diabetes: Diabetes Distress and Care Registry at Tenri (DDCRT 1). Diabet Med. 2012;29(11):1451-1455.
Psychology Research and Behavior Management

\section{Publish your work in this journal}

Psychology Research and Behavior Management is an international, peer-reviewed, open access journal focusing on the science of psychology and its application in behavior management to develop improved outcomes in the clinical, educational, sports and business arenas. Specific topics covered in the journal include: Neuroscience, memory and decision making; Behavior modification and management; Clinical applications; Business and sports performance management; Social and developmental studies; Animal studies. The manuscript management system is completely online and includes a very quick and fair peer-review system, which is all easy to use. Visit http://www dovepress.com/testimonials.php to read real quotes from published authors. 